\title{
Publisher Correction to: Coastal atmospheres: the peninsula of the blessed and the art of noticing
}

\author{
Werner Krauß ${ }^{1}$
}

Published online: 8 October 2021

๑) Springer-Verlag GmbH Germany, part of Springer Nature 2021

\section{Correction to: Maritime Studies}

https://doi.org/10.1007/s40152-021-00241-2

The publication of this article unfortunately contained a mistake. Due to publishers error the Fig. 2 was missing and the legend of Fig. 3 was shown wrong. Below you can see the correct Figs. 2 and 3:

The original article has been corrected.

The original article can be found online at https://doi.org/10.1007/ s40152-021-00241-2.

Werner Krauß

wkrauss@uni-bremen.de

1 University of Bremen, Artec Sustainability Research Center, Bremen, Germany 
Fig. 2 Schlick. Drawing by Werner Krauß
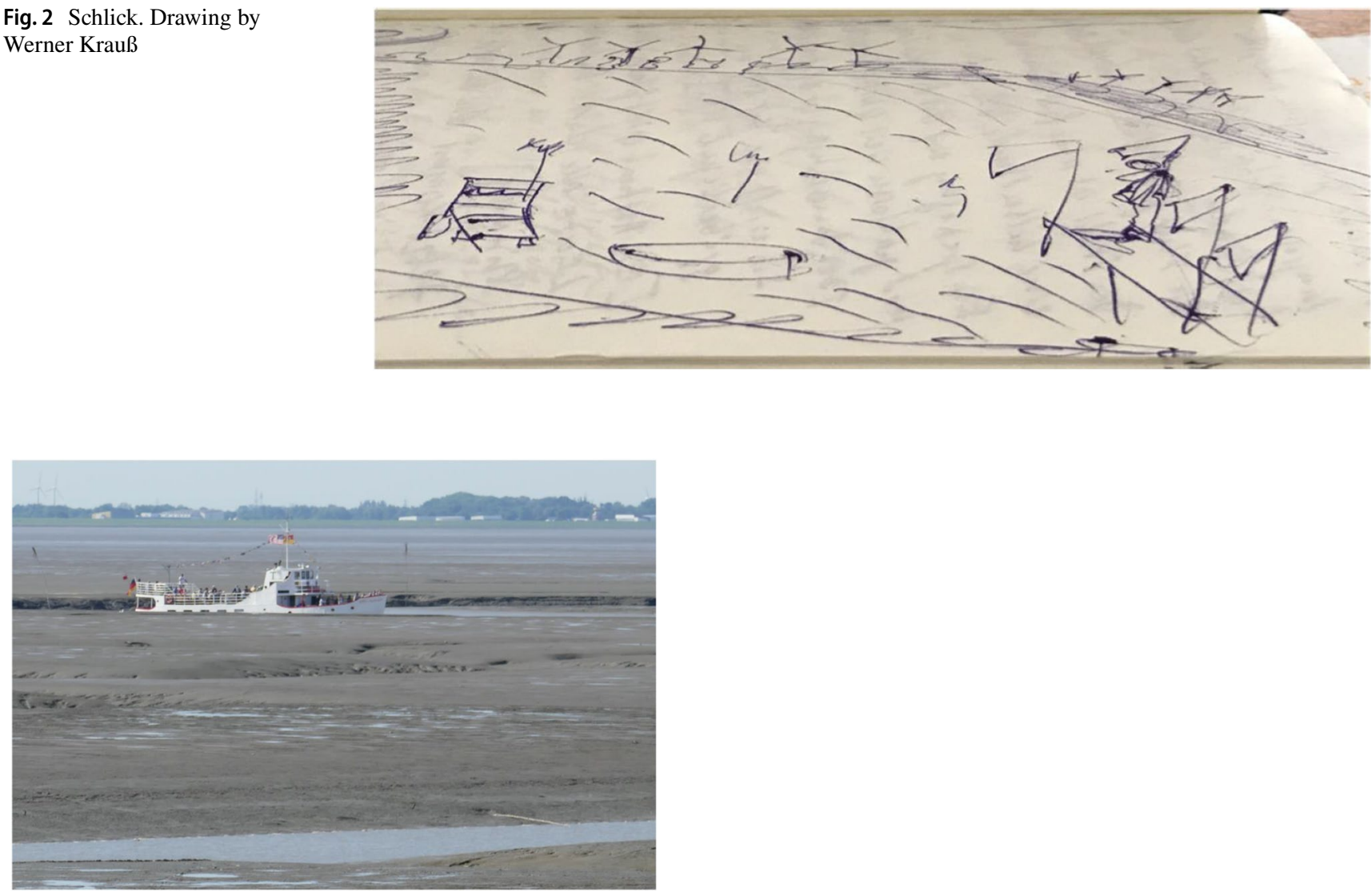

Fig. 3 Etta von Dangast. Photo by Werner Krauß

Publisher's note Springer Nature remains neutral with regard to jurisdictional claims in published maps and institutional affiliations. 